\title{
PEMBELAJARAN METACOGNITIVE SCAFFOLDING SEBAGAI UPAYA MENINGKATKAN KEMAMPUAN BERPIKIR KRITIS MATEMATIS SISWA SMP DALAM MEMECAHKAN MASALAH
}

\author{
Muhamad Zulfikar Mansyur*1, Depi Ardian Nugraha² \\ 1,2Pendidikan Matematika, Universitas Siliwangi \\ Zulfikar.mansyur@unsil.ac.id ${ }^{* 1}$, depi@unsil.ac.id ${ }^{2}$
}

\begin{abstract}
Critical thinking ability is an important ability to have. However, students' mathematical critical thinking skills are still low. Efforts that can be applied are through the Metagontive Scaffolding learning approach. The Metcagontive Scaffolding approach has been proven to be able to improve mathematical communication skills, mathematical literacy, and self-efficacy. This study was conducted to test whether Metagontive Scaffolding can improve the mathematical critical thinking skills of junior high school students better than direct learning. This study uses a quasi-experimental method with a nonequivalent control group design. The population in this study were all eighth grade students in one of the public junior high schools in Bandung. This study uses two classes as a sample from a number of class VIII randomly graded. The data in this study were obtained through the results of the answers to students' mathematical critical thinking abilities. significantly compared to students who participated in direct learning.

Keywords : metacognitive scaffolding learning approach, critical thinking, mathematical problem
\end{abstract}

\begin{abstract}
Abstrak
Kemampuan berpikir kritis merupakan kemampuan yang penting untuk dimiliki. Namun kemampuan berpikir kritis matematis siswa masih rendah. Upaya yang dapat diterapkan adalah melalui pendekatan pembelajaran Metcagontive Scaffolding. Pendekatan Metcagontive Scaffolding telah terbutkti mampu meningkatkan kemampuan komunikasi matematis, literasi matematis, dan self Efficacy. Penelitian ini dilakukan untuk menguji apakah Metcagontive Scaffolding dapat meningkatkan kemampuan berpikir kritis matematis siswa SMP secara lebih baik disbanding pembelajaran langsung. Pada penelitian ini menggunakan metode kuasi eksperimen dengan desain nonequivalent control group design. Populasi dalam penelitian ini adalah seluruh siswa kelas VIII di salah satu SMP Negeri di Bandung. Penelitian ini menggunakan dua kelas sebagai sampel dari sejumlah kelas VIII secara acak kelas.. Data pada penelitian ini diperoleh melalui hasil jawaban kemampuan berpikir kritis matematis siswa, Hasil penelitian menunjukkan bahwa peningkatan kemampuan berpikir kritis matematis siswa yang mengikuti pembelajaran dengan pendekatan metacognitive scaffolding lebih baik secara signifikan dibandingkan dengan siswa yang mengikuti pembelajaran langsung.
\end{abstract}

Kata kunci : pembelajaran metacognitive scaffolding, berpikir kriits, masalah matematis 
Jurnal Lebesgue : Jurnal Ilmiah Pendidikan Matematika, Matematika dan Statistika

Muhamad Zulfikar Mansyur, Depi Ardian Nugraha

Volume 2, No. 2, Agustus 2021 hal.214-224

DOI Artikel : 10.46306/lb.v2i2.81

\section{PENDAHULUAN}

Dalam menghadapi tantangan abad 21 diperlukan kemampuan berpikir tingkat tinggi seperti berpikir kritis, kreatif, dan memecahkan masalah (Kalelioglu \& Gulbahar, 2014). Kemampuan berpikir kritis menjadi salah satu kemampuan penting yang perlu dikuasai. Kemampuan berpikir kritis memungkinkan seseorang menyelesaikan masalah dalam situasi sulit secara efektif dan dengan komunikasi yang akurat (Basri et al, 2019). Berpikir kritis mampu membuat peserta didik siap berpikir pada berbagai disiplin ilmu dan dapat dipakai membantu dalam menjalani karir dan kehidupan nyatanya (Zubaidah, 2010). Berpikir kritis adalah proses yang bertujuan untuk membuat keputusan - keputusan masuk akal sehingga apa yang dianggap terbaik dapat dilakukan dengan benar. Untuk kaitannya dengan matematika, berpikir kritis matematis merupakan kemampuan menggunakan strategi kognitif dalam menggeneralisasi, membuktikan, atau mengevaluasi situasi matematis yang kurang dikenal dengan memanfaatkan kemampuan pengetahuan yang dimilikinya secara efektif (Abdullah, 2013). Berpikir kritis merupakan sebuah proses berpikir yang kompleks yang membutuhkan level kognitif tinggi untuk memproses informasi (Choy dan Cheah, 2009). Berpikir kritis berkaitan dengan taksonomi Bloom analisis, sintesis, dan evaluasi. Lebih jauh berpikir kritis adalah pemikiran reflektif yang beralasan dan berfokus untuk menentukan mengenai apa yang dipercai dan apa yang harus dilakukan. (Ennis, 1993). Walcot dan Lynch (1997) menggambarkan langkah berikir kritis sebagai Mengidentifikasi masalah, informasi relevan, dan semua dugaan tentang masalah tersebut Mengeksplorasi, identifikasi, dan interpretasi segala hubungan yang ada menentukan prioritas alternatif yang ada. Namun Ennis (1996) menyatakan Indikator berpikir kritis yaitu : (1) memberikan penjelasan sederhana (elementary clarification); (2) membangun keterampilan dasar (basic support); (3) membuat simpulan (inference); (4) membuat penjelasan lebih lanjut (advances clarification); (5) menentukan strategi dan taktik (strategi and tactics) untuk memecahkan masalah

Sebuah hasil penelitian yang dilakukan oleh Nuryanti, Zubaidah, \& Diantoro (2018) menghasilkan fakta bahwa kemampuan berpikir kritis siswa SMP masih rendah. Selain itu partisipasi Indonesia pada survei PISA mendapatkan hasil yang kurang memuaskan. Indonesia selalu berada pada peringkat 73 atau berada pada peringkat 7 terbawah pada bisang matematika hal itu menandakan bahwa siswa Indonesia belum terbiasa untuk berpikir secara kritis. (Schleicher, 2019) 
Dalam upaya meningkatkan berpikir kritis siswa maka siswa perlu dibiasakan dengan penyelesaian masalah karena berpikir kritis sangat erat kaitannya dalam kemampuan siswa dalam menghadapi masalah. Masalah dalam matematika identik dengan persoalan matematis. Namun tidak semua soal dapat dikategorikan sebagai masalah. persoalan termasuk sebagai masalah bagi seseorang jika: 1) persoalan tersebut belum ditemui sebelumnya; 2) melibatkan kesiapan mental ataupun pengetahuan dalam menyelesaikannya; (Russefendi, 1991). suatu masalah matematis mempunyai empat elemen, yaitu

1. Situasi yang melibatkan pernyataan awal (initial state) dan pernyataan tujuan (goal state).

2. Situasinya harus melibatkan matematika.

3. Seorang harus menghendaki suatu solusi.

4. Ada beberapa rintangan (blockage) antara pernyataan yang diberikan dan pernyataan yang diinginkannya (the given and desired states).

(Ohio Department of Education, dalam Hoosain, 2001)

Hal serupa diungkapkan Polya (1986) yang membagi masalah menjadi authentic problems dan routie problems. routie problems memiliki karakteristik dapat selesesaikan dengan mensubtitusikan data tertentu ke dalam penyelesaian umum yang dihasilkan sebelumnya, atau dengan mengikuti setiap langkah tanpa perlu menelaah originalitas masalahnya. Berbeda dengan authentic problems yang justru belum diketahui solusi dari masalahnya. Jika didasarkan pada strukturnya masalah terbagi menjadi masalah terstruktur dengan baik (wellstructured), dan masalah tidak terstruktur (ill-structured). Foshay \& Kirkley (2003). Wellstructured problem merupakan masalah sederhana yang dapat diselesaikan dengan mengulamg kembali prosedur dan dapat dikerjakan seperti apa yang sudah dipelajari. Sedangkan masalah tidak terstruktur (ill-structured) merupakan masalah yang melibatkan strategi penyelesaian yang tidak bersyarat bahkan terkadang tidak memiliki tujuan yang jelas. Adanya authentic problems dan ill-structured problems dapat menjadi pengasah kemampuan berpikir matematis siswa yang baik. Dikarenakan sifat masalahnya yang belum jelas dan memaksa siswa untuk bertanya, mencari tahu, dan menggali apa yang diperlukan dan bagaimana masalah tersebut harus diselesaikan. Sehingga daya kritis siswa akan terasah dengan kegiatan tersebut.

Selama proses pembelajaran tentu guru memiliki peran dalam melaksanakan pembelajaran. Walaupun pembelajaran berpusat pada siswa guru harus memiliki pendekatan pembelajaran yang diterapkan dan cocok dalam melatih serta meningkatkan kemampuan berpikir kritis siswa. 
Jurnal Lebesgue : Jurnal Ilmiah Pendidikan Matematika, Matematika dan Statistika

Muhamad Zulfikar Mansyur, Depi Ardian Nugraha

Volume 2, No. 2, Agustus 2021 hal.214-224

DOI Artikel : 10.46306/lb.v2i2.81

Salah satu pendekatan yang dapat diterapkan dan mengasah kemandirian berpikir siswa adalah metacognitive scaffolding.

Scaffolding merupakan sebagai bantuan yang diberikan kepada siswa pada saat siswa mengalami kesulitan dan pelan-pelan mengurangi bantuan tersebut agar siswa lebih mengambil peran dalam menyelesaikan kesulitan yangd dihadapinya. Raiser \&Tabak (2014) menggambarkan ide utama scaffolding sebagai "central idea in scaffolding is that the work is shared between the learner and some more knowledgeable other or agent" yang dapat dimaknai bahwa scaffolding bekerja dimana terdapat siswa yang sedang belajar dan ada siswa lain atau seseorang dengan pengetahuan yang lebih memberikan sejumlah bantuan selama tahap-tahap awal pembelajaran, kemudian secara perlahan mengurangi bantuan. Scaffolding dibutuhkan karena pada dasarnya siswa memiliki potensi yang besar namun menemui keselitan dalam mengorganisir informasi atau kemampuan awal yang telah dimilikinya. Kemampuan mengorganisir ini dikenal sebagai salah satu bentuk kemampuan metacognitive (Awi, 2010). Untuk melibatkan metakognisi siswa pada saat berada pada ZPDnya, siswa membutuhkan bantuan (scaffolding) dari orang yang lebih menguasai secara pengetahuan. Pemberian bantuan disini bukan dalam bentuk memberikan langsung teorema atau rumus mengenai masalah yang dihadapi siswa, namun berupa pertanyaan, arahan, atau perintah yang dapat mengarahkan atau mengaktifkan metakognisinya dalam belajar (Awi, 2010). Yee (Prabawanto, 2019) mengungkapkan bahwa bantuan tanpa metakognitif kurang bisa meningkatkan kesukesan siswa dalam belajar matematika sementara Peter (Prabawanto, 2019) menyatakan bahwa jika hanya bantuan (scaffold) tanpa melibatkan metakognitif membuat siswa lemah dala mengembangkan kemampuannya dalam menyelesaikan masalah. Maka dari itu perlu dikombinasikan scaffold dan metakognitif dalam pendekatan pembelajaran menjadi metacognitive scaffolding karena external dialogue dari sebuah scaffold akan menjadi inner dialogue dari sebuah metakognisi (Holton \& Clarke, 2006).

Setiap siswa merupakan individu yang unik sehingga berbeda satu dengan yang lainnya yang mengakibatkan memiliki kemampuan metakognitif yang berbeda pula. Hal tersebut mengakibatkan guru untuk memberikan bantuan yang berbeda sesuai dengan kondisi yang dialami oleh siswakeadaan ini menjadi habmatan dalam menerapkan pendekatan metacognitive scaffolding pada kelas dengan jumlah siswa puluhan. Untuk mengatasi hal itu maka, digunakan pola belajar kooperatif sebagai kolaborasi dalam penerapan pendekatan pembelajaran metacognitve scaffolding. pendekatan ini akan mengeleompokkan siswa dalam kelompok- 
kelompok kecil berjumlah 4-5 orang. Beberapa penelitian telah mengungkapkan keberhasilan dari pendekatan metacognitive scaffolding dalam meningkatkan kemampuan matematis diantaranya kemampuan komunikasi matematis, Kemampuan pemecahan masalah matematis, Literasi matematis, dan self-efficacy matematis (Prabawant0, 2018; Prabawanto, 2019; Murod, 2015; Mansyur, 2020). Hal tersebut menjadi bukti bahwa bahwa metacognitive scaffolding dapat menjadi alternatif pendekatan pembelajaran dalam upaya meningkatan kemampuan berpikir kritis siswa dalam memecahkan masalah.

\section{METODE PENELITIAN}

Penelitian ini merupakan penelitian kuasi eksperimen yaitu penelitian yang dilakukan untuk melihat hubungan sebab akibat. Perlakuan yang dilakukan terhadap variabel bebas, hasilnya akan terlihat pada variabel terikatnya. Dalam penelitian ini, variabel bebasnya adalah pendekatan pembelajaran metacognitive scaffolding dan variabel terikatnya adalah kemampuan berpikir kritis matematis. Desain penelitian ini adalah nonequivalent control group design. Kelompok eksperimen diberikan perlakuan pembelajaran matematika dengan pendekatan metacognitive scaffolding dan kelompok kontrol diberikan pembelajaran langsung. Sebelum diberikan perlakuan, kedua kelompok ini diberikan pretest untuk mengetahui kemampuan awal siswa. Kemudian, setelah diberikan perlakuan kedua kelompok diberikan posttest.

Adapun desain penelitiannya adalah

$$
\mathrm{O} \quad \mathrm{X} \quad \mathrm{O}
$$

$\mathrm{O} \quad \mathrm{O}$

Keterangan:

$\mathrm{O}:$ Pretest dan postets berupa tes kemampuan berpikir kritis matematis

$\mathrm{X}$ :Pembelajaran matematika dengan pendekatan metacognitive scaffolding.

(Ruseffendi, 2010:53)

Populasi dalam penelitian adalah seluruh siswa kelas VIII di salah satu SMP Negeri di Bandung. teknik Purposive Sampling, digunakan dalam menentukan sampel pada penelitian ini. yaitu dengan mengambil sampel berdasarkan pertimbangan tertentu (Sukardi, 2003: 64). Dalam melaksanakan penelitian peneliti tidak dapat membuat kelas baru, maka peneliti menggunakan kelas yang sudah ada di sekolah tersebut. Setelah dilakukan purposive smpling terpilih satu kelas eksperimen yang mendapat pembelajaran matematika dengan pendekatan 
Jurnal Lebesgue : Jurnal Ilmiah Pendidikan Matematika, Matematika dan Statistika

Muhamad Zulfikar Mansyur, Depi Ardian Nugraha

Volume 2, No. 2, Agustus 2021 hal.214-224

DOI Artikel : 10.46306/lb.v2i2.81

metacognitive scaffolding dan kelas lain sebagai kelas kontrol yang mendapat pembelajarn matematika pembelajaran langsung.

\section{HASIL PENELITIAN DAN PEMBAHASAN}

Untuk mengetahui apakah peningkatan kemampuan berpikir kritis matematis siswa yang mendapatkan pembelajaran dengan pendekatan metacognitive scaffolding lebih baik dibandingkan dengan siswa yang mendapatkan pembelajaran langsung, maka terlebih dahulu dilakukan pretes pada kedua kelas sampel. Hal ini dilakukan untuk mengetahui kemampuan berpikir kritis matematis awal kedua kelas sampel. Berdasarkan hasil analisis data terhadap hasil pretes, diperoleh hasil sebagai berikut

Tabel 1. Deskrpsi Kemampuan berpikir Kritis Matematis

\begin{tabular}{ccccccc}
\hline \multirow{2}{*}{ Kelas } & \multicolumn{2}{c}{ Pretes } & \multicolumn{2}{c}{ Post-Test } & \multicolumn{2}{c}{ Indeks Gain } \\
\cline { 2 - 7 } & Mean & SD & Mean & SD & Mean & SD \\
\hline Eksperimen & 24.857 & 13.5845 & 52.714 & 23.6190 & .3920 & .28220 \\
\hline Kontrol & 26.571 & 15.4716 & 41.714 & 20.9321 & .2290 & .23277 \\
\hline
\end{tabular}

Tabel 2. Uji Normalitas Data Pretest.

Tests of Normality

\begin{tabular}{|c|r|r|r|r|r|r|}
\hline \multirow{2}{*}{ KELAS } & \multicolumn{3}{|c|}{ Kolmogorov-Smirnov $^{\mathrm{a}}$} & \multicolumn{3}{|c|}{ Shapiro-Wilk $^{-}$} \\
\cline { 2 - 7 } & Statistic & \multicolumn{1}{c|}{$\mathrm{df}$} & \multicolumn{1}{c|}{ Sig. } & Statistic & \multicolumn{1}{c|}{$\mathrm{df}$} & \multicolumn{1}{c|}{ Sig. } \\
\hline EKSPERIME & .239 & 35 & .000 & .855 & 35 & .000 \\
PRETES N & & & & & & \\
KONTROL & .150 & 35 & .044 & .931 & 35 & .030 \\
\hline
\end{tabular}

bahwa data pretes berdistribusi tidak normal sehingga untuk mengetahui kemampuan berpikir kritis matematis awal kelas eksperimen dan kelas kontrol digunakan statistik non-parametrik yaitu dengan uji Mann-Whitney.

Tabel 3. Uji Mann Whitney Data Pretest

Test Statistics ${ }^{\mathrm{a}}$

\begin{tabular}{|l|r|}
\hline & PRETES \\
\hline Mann-Whitney U & 541.500 \\
\hline
\end{tabular}




\begin{tabular}{|l|r|} 
Wilcoxon W & 1171.500 \\
$Z$ & -.843 \\
Asymp. Sig. (2- & .399 \\
tailed) & \\
\hline
\end{tabular}

Dari hasil analisis terhadap uji Mann-Whitney tersebut diperoleh kesimpulan bahwa kemampuan berpikir kritis matematis awal siswa kelas eksperimen dan siswa kelas kontrol adalah sama.

Selanjutnya akan dilihat peningkatan kemampuan berpikir kritis matematis kedua kelas sampel melalui analisis data indeks gain.

Tabel 4. Uji Normalitas Data Indeks Gain

\section{Tests of Normality}

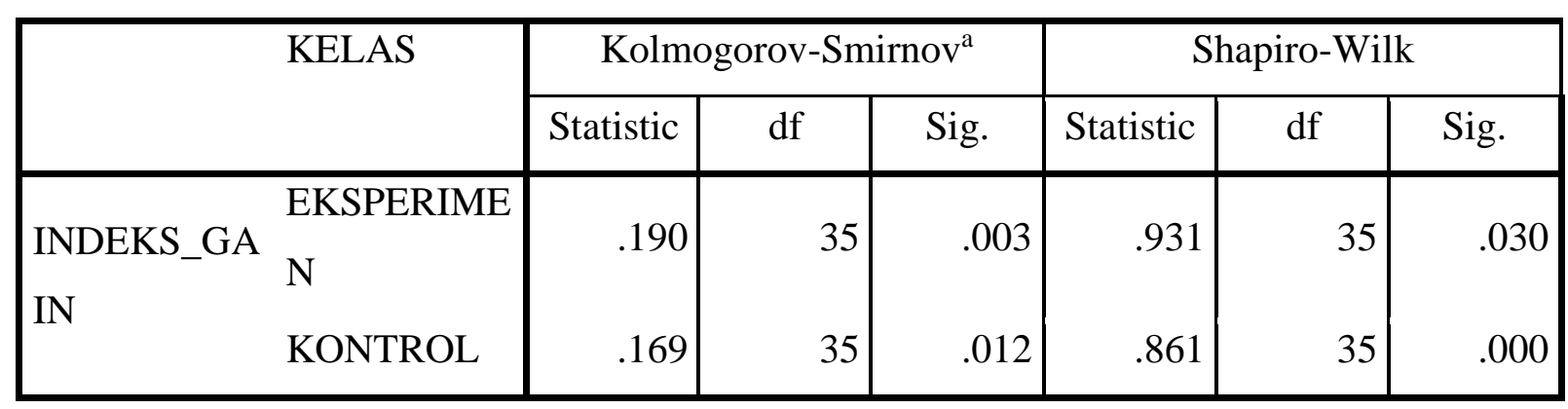

Berdasarkan hasil analisis data indeks gain terhadap kedua kelas sampel, didapatkan hasil bahwa data indeks gain tidak berdistribusi normal sehingga untuk mengetahui peningkatan kemampuan berpikir kritis matematis siswa kelas eksperimen dan siswa kelas kontrol digunakan statistik non-parametrik yaitu dengan uji Mann-Whitney.

Tabel 5. Uji Mann Whitney Data Indeks Gain

\section{Test Statistics ${ }^{\mathrm{a}}$}

\begin{tabular}{|l|r|}
\hline & $\begin{array}{r}\text { INDEKS_G } \\
\text { AIN }\end{array}$ \\
\hline Mann-Whitney U & 394.000 \\
Wilcoxon W & 1024.000 \\
Z & -2.571 \\
Asymp. Sig. (2- & .010 \\
tailed) & \\
\hline
\end{tabular}


Jurnal Lebesgue : Jurnal Ilmiah Pendidikan Matematika, Matematika dan Statistika

Muhamad Zulfikar Mansyur, Depi Ardian Nugraha

Volume 2, No. 2, Agustus 2021 hal.214-224

DOI Artikel : 10.46306/lb.v2i2.81

Berdasarkan analisis uji Mann-Whitney diperoleh kesimpulan bahwa peningkatan kemampuan berpikir kritis matematis siswa kelas eksperimen lebih baik daripada siswa kelas kontrol.

Berdasarkan Tabel 1. Diperoleh hasil bahwa peningkatan kemampuan berpikir kritis matematis siswa kelas dengan pendekatan metcagonitive scaffolding lebih baik daripada kelas dengan pendekatan langsung. Rata-rata indeks gain siswa pada kelas eksperimen berada pada kategori sedang, sedangkatn rata-rata indeks gain siswa pada kelas kontrol berada pada kategori rendah Berdasarkan hasil ini, diperoleh suatu kesimpulan bahwa siswa pada kelas eksperimen memiliki kualitas peningkatan kemampuan berpikir kritis matematis yang cukup baik dibandingkan kualitas peningkatan kemampuan berpikir kritis matematis pada kelas kontrol yang berada pada tingkatan rendah. Meskipun demikian kedua kelas sampel tetap mengalami peningkatan kemampuan berpikir kritis matematis hanya saja kualitas peningkatan kemampuan berpikir kritis matematis siswa kelas eksperimen lebih baik daripada peningkatan kemampuan berpikir kritis matematis siswa pada kelas kontrol.

Pendekatan metacognitive scaffolding menghadapkan siswa dengan masalah matematis yang diajukan oleh guru. Lalu siswa berusaha memahami masalah yang diajukan lalu mengidentifiksi hubungan antar unsur dari masalah yang diajukan dan merancang strategi untuk menyelesaikan masalah. Hal itu membuat siswa terbiasa untuk melakukan proses - proses berpikir kritis. Pada awal meghadapi masalah siswa akan diminta unutk membuat penjelasan sederhana mengenai masalah yang dihadapinya. Jika ada siswa yang menemui kesulitan makatemannya akan membantu namun jika masih sulit maka guru akan meberikan pertanyaan - pertanyaan atau arahan mengenai permasalahan yang dihadapi. Hal serupa diungkapkan oleh Hasruddin (2009) bahwa berpikir dimulai dengan sebuah pertanyaan. Pertanyaan tidak perlu diungkapkan namun bisa saja hanya ada dalam otak pikiran. Pertanyaan yang ada dalam pikiran tersebut akan menjadi stimulan untuk melakukan penggalian lebih jauh dari apa yang sedang dipikirkan. Efek dari bantuan baik dari guru maupun siswa dengan more knowledge ini berdampak pada mulai terbangunnya keterampilan dasar siswa. Selanjutnya siswa akan mencoba menyimpulkan sendiri dari apa yang telah dipahami setelah mendapatkan bantuan (scaffold) lalu menyusun strategi untuk memecahkan masalah yang diberikan. pemikir kritis mampu menganalisis, mengevaluasi informasi, memunculkan pertanyaan, menyusun pertanyaan dari masalah tersebut dengan jelas, mengumpulkan dan menilai informasi yang relevan menggunakan ide-ide abstrak, berpikiran terbuka, serta mengomunikasikannya 
dengan efektif. (Duron, R., Limbach, B., \& Waugh, W. 2006). Langkah - langkah tersebut selalu dibiasakan dalam pendekatan metacognitive scaffolding sehingga berpengaruh dengan kemampuan berpikir kritis matematis siswa. Dalam pembelajaran matematika dengan pendekatan metacognitive scaffolding yang diterapkan oleh peneliti berkombinasi dengan model belajar kooperatif. Pada pembelajaran metacognitive scaffolding guru mengajukan masalah lalu siswa mencoba menyelesaikan masalah yang diajukan guru dengan bekerja secara kooperatif dalam kelompoknya yang berjumlah 3-4 orang yang heterogen. Dalam usaha menyelesaikan masalah matematis siswa akan mengalami ketidaksetimbangan (disequilibrium), pada saat ketidaksetimbangan tersebut siswa akan berusaha bertanya kepada dengan temannya yang memiliki kemampuan lebih tinggi darinya untuk menyelesaikan masalah matematis yang diajukan oleh guru sehingga terjadilah keadaan setimbang (equilibrium) yang baru, dimana keadaan setimbang ini berada pada tingkat intelektual yang lebih tinggi dari sebelumnya.

Pada hasil analisis diketahui bahwa pembelajaran langsung juga memberikan peningkatan kemampuan berpikir kritis matematis pada siswa. Terdapat beberapa hal yang menjadi penyebab meningkatnya pemecahan masalah matematis pada pembelajaran langsung diantaranya seperti yang telah diungkapkan sebelumnya yaitu equilibrasi. Pada pembelajaran langsung guru melakukan apersepsi untuk mengetahui sejauh mana konsep syarat dikuasai siswa sebelum konsep baru dijelaskan. lalu guru menjelaskan tentang konsep yang akan dipelajari dilanjutkan dengan memberikan contoh penyelesaian matematis berkaitan dengan konsep yang dibahas. Jika ada yang kurang dipahami oleh siswa maka siswa diperbolehkan untuk bertanya. Proses bertanya ini dimanfaatkan oleh siswa untuk mengatasi kekurangpahaman akan materi atau disequilibrium agar menjadi equilibrium dengan pemahaman intelektual yang lebih baik daripada sebelumnya. Setelah siswa memperoleh pemahaman terhadap konsep yang diberikan, guru melanjutkan pembelajaran dengan memberikan soal latihan. Pada tahap latihan ini siswa akan mencoba mengaplikasikan konsep yang telah diterimanya. Hal ini sesuai dengan apa yang dikemukakan oleh Ausebel (Dahar, 1988:181) belajar bermakna akan terjadi apabila informasi baru dapat dikaitkan pada subsume yang ada dalam struktur kognitif.Jika informasi yang baru ini tidak memiliki keterkaitan dengan subsumer yang ada dalam struktur kognitif maka siswa hanya mengalami belajar hafalam. Pendapat Ausubel iniah yang mendasari adanya apersepsi pada awal sebelum pembelajaran dan pada pemberian latihan agar konsep yang diterima siswa memiliki keterkaitan dan siswa 
mengalami pembelajaran secara bermakna. belajar bermakna dan proses equilibrasi inilah yang diduga dapat meningkatkan kememapuan pemecahan masalah matematis siwa yang menerima pembelajaran langsung.

Dari uraian diatas, baik siswa dengan pendekatan metacognitive scaffolding maupun pembelajaran langsung sama-sama mengalami peningkatan kemampuan pemecahan masalah matematis. Namun siswa dengan pendekatan metacognitive scaffolding memiliki peningkatan yang lebih baik. Diduga hal ini karena adanya bantuan/scaffolding yang bersifat metakognitif sehingga siswa memonitor dan mengevaluasi dirinya sendiri, selain itu interkasi sosial dalam pola belajar kooperatif juga menjadi faktor yang diduga meningkatkan kemampuan berpikir kritis matematis siswa. Kedua faktor tersebut diduga menjadi penyebab lebih baiknya peningkatan kemampuan berpikir kritis matematis siswa dibanding dengan pembelajaran langsung.

\section{KESIMPULAN}

Berdasarkan pembahasan maka dapat disimpulkan bahwa peningkatan kemampuan berpikir kritis matematis siswa dengan pendekatan pembelajaran metacognitive scaffolding lebih tinggi dibandingkan dengan pembelajaran langsung. Pemberian bantuan (scaffold) yang bersifat metakognitif dan sementara menjadikan siswa untuk berpikir secara mandiri dan berpengaruh kepada kemampuan berpikir krits matematisnya.

Pendekatan Metacognitive Scaffolding dapat dijadikan alternatif pembelejaran untuk meningkatkan kemampuan matematis siswa. Penelitian terhadap pembelajaran dengan pendekatan metacognitive scaffolding disarankan untuk dilanjutkan dengan karakteristik populasi yang berbeda serta kompetensi matematis lainnya dengan materi atau pokok bahasan yang berbeda pula.

\section{DAFTAR PUSTAKA}

Abdullah, I. H. (2016). Berpikir kritis matematik. Delta-Pi: Jurnal Matematika dan Pendidikan Matematika, 2(1).

Basri, H. (2019). Investigating Critical Thinking Skill of Junior High School in Solving Mathematical Problem. International Journal of Instruction, 12(3), 745-758.

Choy, S. C., \& Cheah, P. K. (2009). Teacher perceptions of critical thinking among students and its influence on higher education. International Journal of teaching and learning in Higher Education, 20(2), 198-206.

Dahar, R. W. (1988). Teori-Teori Belajar.Jakarta: Erlangga. 
Duron, R., Limbach, B., \& Waugh, W. (2006). Critical thinking framework for any discipline. International Journal of Teaching ad Learning in Higher Education, 17(2), 160-166.

Ennis, R. H. (1993). Critical thinking assessment. Theory into practice, 32(3), 179-186.

Ennis. (1996). Critical Thingking. New York: Prentice Hall. Inc.

Foshay, R. dan Kirkley, J.(2003). Principles for Teaching Problem Solving

Hasruddin, H. (2009). Memaksimalkan kemampuan berpikir kritis melalui pendekatan kontekstual. Jurnal Tabularasa, 6(1), 48-60.

Holton, D., \& Clarke, D. (2006). Scaffolding and metacognition. International journal of mathematical education in science and technology, 37(2), 127-143.

Hoosain, E. (2001). What Are Mathemathical Problems. Augusta: Augusta State University

Mansyur, M. Z., \& Sunendar, A. (2020). Meningkatkan Kemampuan Pemecahan Masalah Matematis Siswa melalui Pendekatan Metacognitive Guidence. Edumatica: Jurnal Pendidikan Matematika, 10(2), 19-27.

Nuryanti, L., Zubaidah, S., \& Diantoro, M. (2018). Analisis kemampuan berpikir kritis siswa SMP. Jurnal Pendidikan: Teori, Penelitian, dan Pengembangan, 3(2), 155-158.

Prabawanto, S. (2018, May). The enhancement of students' mathematical self-efficacy through teaching with metacognitive scaffolding approach. In Journal of Physics: Conference Series (Vol. 1013, No. 1, p. 012135). IOP Publishing.

Prabawanto, S. (2019). ENHANCEMENT OF STUDENTS'MATHEMATICAL COMMUNICATION UNDER METACOGNITIVE SCAFFOLDING APPROACH. Infinity Journal, 8(2), 117-128.

Reiser, B. J., \& Tabak, I. (2014). Scaffolding. In The Cambridge Handbook of the Learning Sciences, Second Edition (pp. 44-62). Cambridge University Press.

Ruseffendi, E.T. (1991). Pengantar kepada Membantu Guru Mengembangkan Kompetensinya dalam Pengajaran Matematika untuk Meningkatkan CBSA. Bandung: Tarsito

Schleicher, A. (2019). PISA 2018: Insights and Interpretations. OECD Publishing.

Wolcott, S. K., \& Lynch, C. L. (1997). Critical thinking in the accounting classroom: A reflective judgment developmental process perspective. ACCOUNTING EDUCATIONGREENWICH-, 2, 59-78.

Zubaidah, S. (2010, January). Berpikir Kritis: kemampuan berpikir tingkat tinggi yang dapat dikembangkan melalui pembelajaran sains. In Makalah Seminar Nasional Sains dengan Tema Optimalisasi Sains untuk memberdayakan Manusia. Pascasarjana Unesa (Vol. 16, pp. 1-14). 